\title{
Technology and Application for Prevention of Lagging Water-bursting from Roadway
}

\author{
Jianjun Shen ${ }^{1 a}$, Yunfeng Zhang ${ }^{1,2 b}$, Mingdong Zhao ${ }^{1 \mathrm{c}}$ \\ ${ }^{1}$ College of Geoscience and Surveying Engineering, China University of Mining and Technology \\ (Beijing), Beijing 100083, China \\ ${ }^{2}$ Shandong Geological Engineering Investigation Institute, Ji'nan 250014, China \\ ashenjianjun11987@163.com, byfeng_zhang@163.com, c302688299@qq.com
}

\begin{abstract}
Keywords: Lagging water-bursting; Time effect; Water inrush prevention measures; Supporting parameters

Abstract. In view of the roadway threatened by confined water are prone to water-inrushing during operation service, industrial test of supporting parameter optimization had been carried out in deep mine. This paper analyzes time effect of water inrush and prevention measures, and put forward the optimization of support parameters to enhance outburst-prevention potential. According to engineering analogy method, this paper provided a preliminary support plan. Based on suspension theory and Ansys software, the roadway supporting parameters and installation load were optimized. Through field application and mine pressure observation, the results showed that the maximal displacement induced-by the roadway roof and floor deformation near fault fracture zone is $132 \mathrm{~mm}$. The maximum value of roof separation in shallow is $15 \mathrm{~mm}$, the maximum value in deep is $8 \mathrm{~mm}$. The surrounding rock has been effectively controlled.
\end{abstract}

\section{Introduction}

Water inrush did not occur when faults exposed by excavation, while occur due to deformation and failure of roadway surrounding rock during mine operational service within a few months, or years even. The above phenomenon is called roadway lagging water inrush. Roadway lagging water inrush caused serious impact on mine efficient production and worker safety, even caused flooding.

The maximum mining depth of No.15 coal seam is $-950 \mathrm{~m}$, which belongs to deep mining area. According to the experience of deep mining in recent years, the main problems affecting safety mining in the region are following points: (1)large deformation, which increases supporting difficulty, and reduces the thickness of effective impermeable layer. (2)the large hydrostatic pressure of aquafer, which increases risk of water inrush. Roadway lagging water inrush had occurred times in the history of the mine, which makes the study of lagging water inrush meaningful.

Wu Qiang ${ }^{[1,2]}$, Liu Weitao ${ }^{[3]}$ based on fluid-solid coupling theory, and by FLAC3D software, simulated the whole process of lagging-water inrush, explained the lagging water inrush mechanism. $\mathrm{Xu} \mathrm{Xuehan}^{[4]}$ based on engineering geological mechanics, analysed lagging water bursting mechanism, put forward three interactive factors, including engineering, rock and groundwater, proposed confined water chemical erosion action, physical weakening effect and mechanical action of high confined water. Li Lianchong ${ }^{[5]}$ simulated the whole process of collapse column activation, crack initiation - expansion, formation of water inrush channel under the interaction of mining disturbance and high pressure water stress using the finite element method, and analyzed the effect of collapse column height,water pressure on water inrush lagging time. Hu Yaoqing ${ }^{[6]}$ established a mathematical model of roadway hysteretic water bursting, which was used to analyze lagging water bursting by the method of finite element.

By analyzing the reason of roadway lagging water inrush, this paper suggested that, effective impermeable layer in surrounding rock, which under effect of underground pressure and water pressure in a long-term, became failure and connected to high confined water, leading to formation of water inrush channel. Based on previous theoretical studies, the mechanism of preventing water inrush and specific measures for preventing water inrush were posed. The initial supporting schemes was made under the geological conditions, supporting parameters and installation load 
were optimized based on Ansys software.

315 track roadway is located in No.3 district expanded area, which that is 315 transport roadway in east. Immediate roof of \#15 coal seam is siltstones, about $6 \mathrm{~m}$ thick.; Main roof is sandstone, about $15 \mathrm{~m}$ thick, which is direct water-filled aquifer with rich and moderate water abundance. Water inrush may occur in fault fractured zone. of limestone III after multi-layer mining, will supply to the No.5 limestone water and No.6 limestone were supplied via fault fracture zone by Ordovician limestone with high water level underlying \#15 coal seam

\section{Methods}

As for time effect of water-inrush in the fracture zone, Wu Qiang and Zhou Ruiguang ${ }^{[7-9]}$ proposed the ratio of preventing water inrush potential $U_{P}$ and the water inrush potential $U_{I}$, i.e.:

$$
R=U_{P} / U_{I}
$$

where $U_{I}$ is a function of groundwater pressure $P$, water quantity $Q$, permeability coefficient $K$, etc. i.e.:

$$
U_{I}=f(p, q, k 、 x)
$$

Prevention of water inrush potential is inherent in the rock mass, which is related to a historical period rock deformation $\varepsilon_{e}$, the roadway excavation deformation $\varepsilon_{k}$, environmental factors $V$, distance from the aquifer water inrush $L$ and mechanical properties of the rock, i.e.

$$
U_{P}=f\left(\varepsilon_{e}, \varepsilon_{k}, V 、 L 、 \sigma 、 E 、 Y\right)
$$

where $\varepsilon_{e} 、 \varepsilon_{k} 、 V$ are related to roadway excavation, roadway section size, ground stress, mechanical effect of rock mass structure and time effect, which is a changing amount, the inherent prevention water inrush potential in original rock will be reduced as long as rock excavation, namely engineering geomechanics action process before the water inrush can make prevention water inrush potential reaches a critical value, that is the water inrush potential.

If the ratio $R=1$, the surrounding rock is in critical state; if the ratio $R<1$, water inrush is prone to occur; if the ratio $R=S>1$, water inrush would not occurs during excavation and operation, with $S$ called prevention water inrush safety coefficient, while $L$ and corresponding $S$ are referred to as Safety rock mass thickness for prevention water inrush.

As shown in Fig.1, water inrush does not occur during excavation, i.e., the roadway surrounding rock has a certain prevention water inrush ratio $R_{0}$, which is less than certain range and more than 1 .

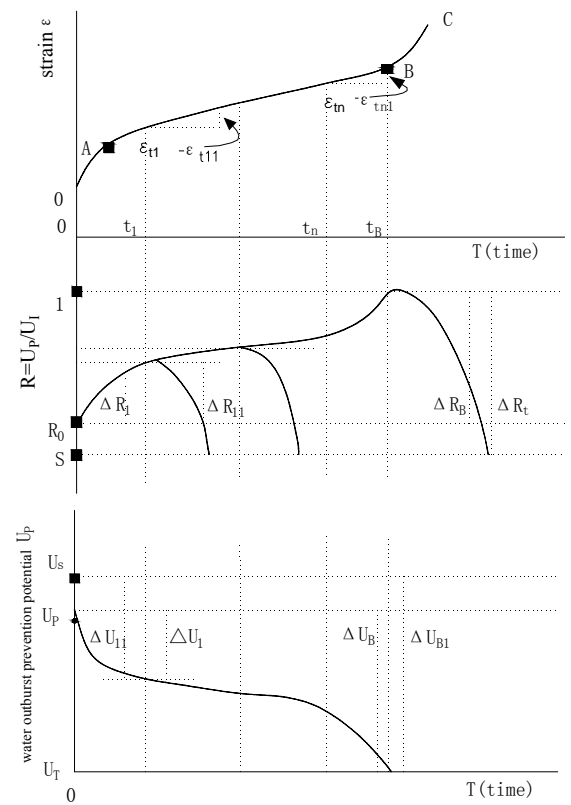

Fig.1 Time effect of water inrush

At this point, roadway surrounding rock has the potential of prevention water inrush $U_{P 0}$, water inrush would not occur. After roadway excavation, surrounding rock generates flow deformation, 
which results in prevention water inrush potential $U_{P 0}$ decreasing, and the ratio $R$ decreasing. When the surrounding rock is in the accelerating rheological phase, the ratio $R$ reduced to close to 1, with the water inrush is in a critical state. Corresponding roadway surrounding rock prevention water outburst potential reduces to the threshold of water outburst potential $U_{T}$, which is equal to the potential of water outburst, water inrush will soon occur. Therefore, in order to prevent water inrush, corresponding measures should be taken.

Measures fall into two categories ${ }^{[9]}$, a class of consumpting water inrush potential; a class of increasing the prevention water inrush potential, or protecting the water inrush potential prevention, which both measures make the ratio $R$ increased to $S$, water inrush would not occur.

\section{Results and Discussion}

Purpose of roadway supporting design is to determine more economical and secure support form and parameters while maintaining the stability of the roadway to ensure deformation of roadway surrounding rock, which could meet requirements of roadway service and ensure roadway lagging water inrush does not occur during the roadway operation. Firstly, this paper used engineering analogy method to determine the initial support program on the basis of previous experience.

After roadway excavation, a range of damage zone emerged in sides, roof and floor. Bolt supporting maintains rock stability within the scope of the destruction zone (Fig. 2). Scientific bolt supporting design should make each bolt play its biggest role instead of simply install bolt in the roof. According to previous research results, the typical supporting theories include beam theory, elastoplastic loose circle theory, wedge reinforcement theory, arch theory, suspension theory.

Based on the suspension theory, the destruction zone is suspended on a stable rock formations. The main is to determine destruction zone range (roadway damage depth $C$, roof damage height $b$ ), load value (roof load collection degree $Q_{r}$, roadway load collection degree $Q_{s}$ ) (Fig.3), as well as specific parameters of bolting support.

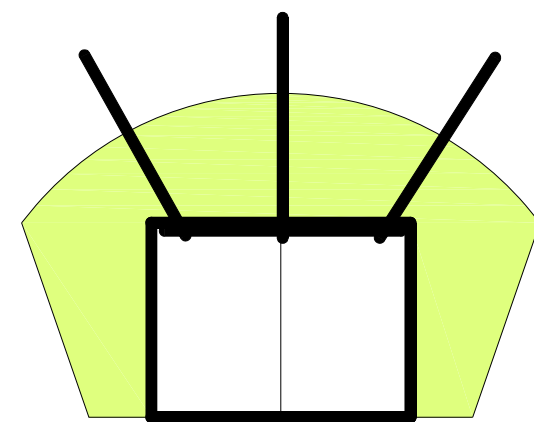

Fig.2 Damaged area load hanging on the two sides stability rock

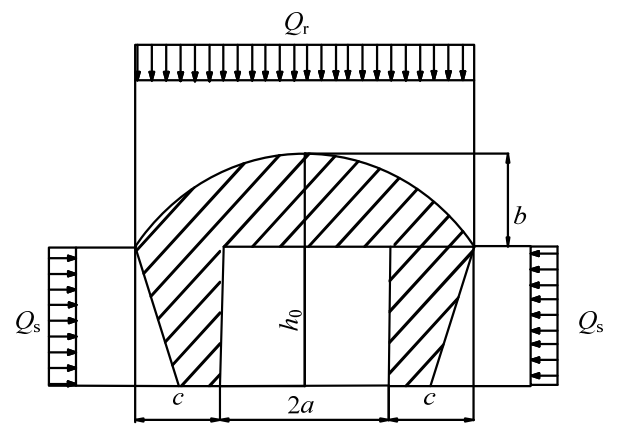

Fig.3 Calculation chart of bolting main parameters

According to suspension theory, the following parameters were ditermined: (1) $900 \times 800 \mathrm{~mm}$ for array space between bolts; (2) $\Phi=20 \mathrm{~mm}, \mathrm{~L}=2200 \mathrm{~mm}$ for high strength anchor; (3)grouting-bolts in fault fracture zone.

As shown in Fig.4, bolt parameters was determined based on Ansys software. To obtain reasonable installation loads, the modes were conduted by changing bolt installation loads, the effect of non abscission layer and minimum tensile stress were obtained in roof.

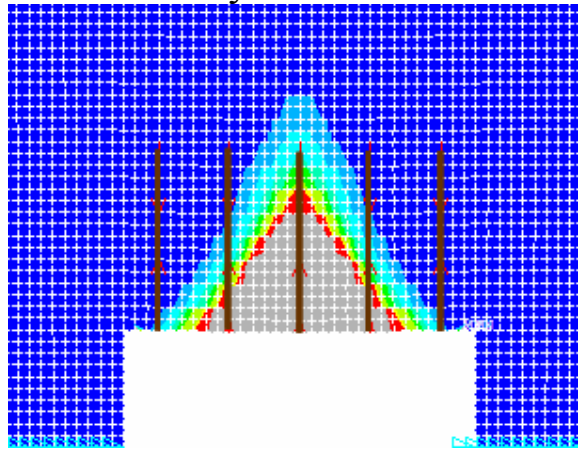

(a) load $1.0 \mathrm{t}$

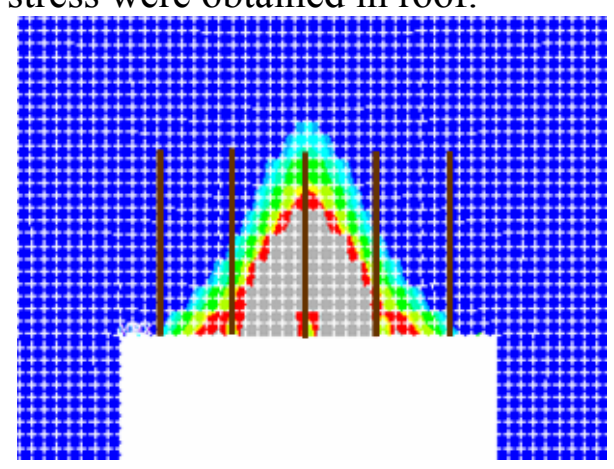

(b) load 2.0t 


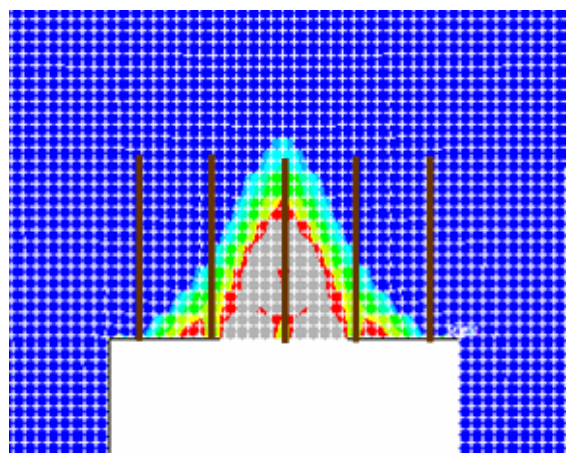

(c) load 3.0t

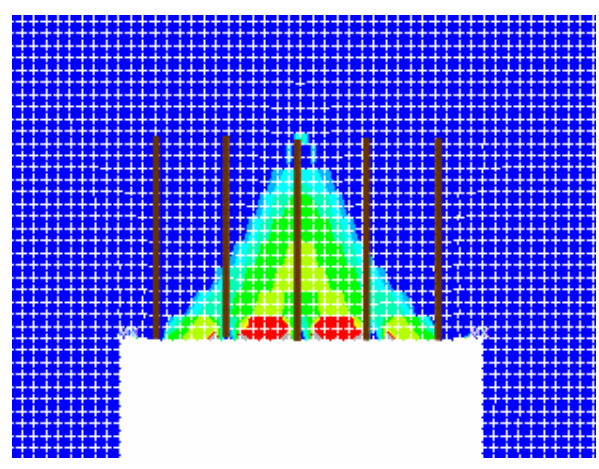

(d) load 4.0t

Fig.4 Stress distribution and deformation

In the model, bolt installation stress increased from 1t to 4t, as shown in Fig.4. In Fig.4, the gray area is the tension zone. With roof tensile stress zone completely eliminated, $4.0 t$ installation load could achieve the best combination, so minimum bolt installation stress should be set $4 \mathrm{t}$.

According to rock pressure observation, a group observation station every $100 \mathrm{~m}$ were set in 315 track roadway, with 1 group of roof separation observation point, and 1 group of "+" character distribution observation points and 1 group of anchor stress observation point in every observation station.

The results in $3 \#$ observation station are shown in Fig.5 and Fig.6, maximum displacement between roadway roof and floor is $132 \mathrm{~mm}$, with an average $66 \mathrm{~mm}$, the average displacement velocity is $1.71 \mathrm{~mm} / \mathrm{d}$; while maximum displacement between two sides is $123 \mathrm{~mm}$, with an average $62 \mathrm{~mm}$, the average displacement velocity is $1.59 \mathrm{~mm} / \mathrm{d}$. The maximum separation amount in shallow is $15 \mathrm{~mm}, 0.19 \mathrm{~mm} / \mathrm{d}$ on average, while in deep, the maximum separation value is $8 \mathrm{~mm}$, $0.10 \mathrm{~mm} / \mathrm{d}$ on average.

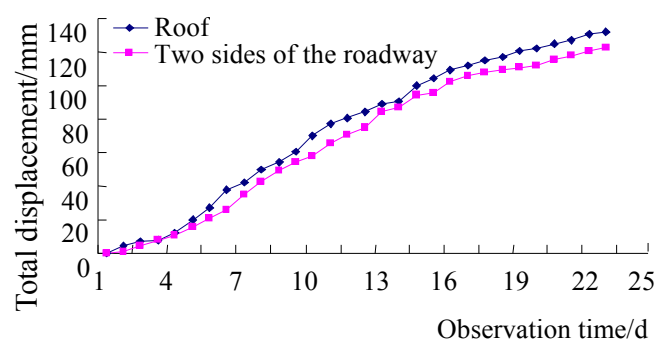

Fig.5 Deformation curve of 3\# observation station

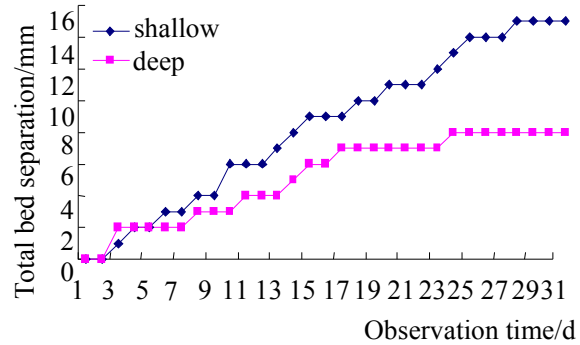

Fig.6 Roof separation curve of $3 \#$ observation station

\section{Conclusions}

This paper put forward supporting preliminary plans of roadway in special geological conditions, used high-strength prestressed bolt and prestressed nest anchor, and adopted high-strength screw grouting anchor in the fracture zone.

According to the finite element analysis, the installation stress can decrease or eliminate tensile stress area in the roof, eliminate the separation of roof strata, which could obtain the best effect. In the geological conditions, the minimum installation bolt stress is $4 \mathrm{t}$.

Maximum displacement of roadway roof and floor is $132 \mathrm{~mm}$, largest movement of two side is $123 \mathrm{~mm}$, roof separation maximum amount is $15 \mathrm{~mm}$ in shallow, while $8 \mathrm{~mm}$ in depth. Roadway surrounding rock well controlled without water inrush phenomenon, indicating that high-strength anchor and grouting bolt are technically feasible.

\section{References}

[1] Qiang Wu, Bin Zhu, Jianmin Li. Numerical simulation of lagging water-inrush mechanism of rock roadways near fault zone[J]. Journal of China University of Mining \& Technology, 2008, 37(6): 780-785. (In Chinese) 
[2] Qiang Wu, Bin Zhu, Shouqiang Liu. Flow-solid coupling simulation method analysis and time identification of lagging water-inrush near mine fault belt[J]. Chinese Journal of Rock Mechanics and Engineering, 2011, 30(1):93-104. (In Chinese)

[3] Weitao Liu, Jianjun Shen, Lianfu Wang. Numerical simulation on lag water-bursting at fault zone based on $\mathrm{FLAC}^{3 \mathrm{D}}[\mathrm{J}]$. Journal of Liaoning Technical University, 2012, 31(5):646-649. (In Chinese)

[4] Xuehan Xu. New field of engineering geomechanics--Study on prediction of water inrush in coal mine[C].Professional Committee of Engineering Geology of the Geological Society of China. The fourth national conference on engineering geology sinica (No.3). Beijing: Ocean Press, 1992:1733-1742. (In Chinese)

[5] Lianchong Li, Chun'an Tang, Yujun Zuo. Mechanism of hysteretic groundwater inrush from coal seam floor with karstic collapse columns [J]. Coal Journal, 2009, 34(9): 1212-1216. (In Chinese)

[6] Yaoqing Hu, Dong Yang, Yangsheng Zhao. The mechanism and simulation of water lag outburst from tunnels[C]. The Chinese Society for Rock Mechanics and Engineering. The sixth national academic conference proceedings of rock mechanics and engineering. Beijing: Science Press, 2000:360-362. (In Chinese)

[7] Weitao Liu, Qiang Wu. Fracture lagging deep mining water inrush mechanism and numerical simulation technology[M].Beijing: Coal industry Press, 2010:113-115. (In Chinese)

[8] Ruiguang Zhou, Ronghua Ling, Binfang Cheng. Study on differential flow deformation and destruction[J]. Journal of Engineering Geology, 1997, 5 (1) : 59-64. (In Chinese)

[9] Ruiguang Zhou, Binfang Cheng, Guijun Ye, et al. Time effect of water bursting in fault rupture zone[J]. Journal of Engineering Geology, 2000， 8(4): 411-415. (In Chinese) 